\title{
"My Name is A-on-the-cheek": Managing Names and Name Signs in American Sign Language-English Team Interpretation
}

\author{
Giulia Petitta, Valerie Dively, Mark Halley, Marc Holmes and \\ BRENDA Nicodemus
}

Gallaudet University, Washington, DC, USA

Interpreters face challenges when rendering names between languages. First, names may be unknown to the interpreter or contain culturally specific information. Further, names lack contextual clues that aid the decoding process. Finally, names may be pronounced in a manner that is difficult to understand (e.g., rapidly or with an accent). Spoken language interpreters have the option of repeating names in their original form; however, signed language interpreters work between languages produced in distinct language modalities (sign-speech) that share no phonological features; thus, names cannot simply be reproduced across languages. In this study we created a mock scenario between two interlocutors (a hearing computer specialist and a deaf international student) who enacted a training session in which they deliberately incorporated names. The interlocutors repeated this training session three times, each with a different team of interpreters. We report strategies used by the teams to convey names in their interpretations.

KEYWORDS signed language, interpreting, translation, name signs, anthroponyms, toponyms

\section{Introduction}

Navigating a trip in another country can be a disorienting experience, especially when travellers encounter the name of a city or country that is dissimilar from what is used in their own language. For example, an English speaker who believes she has arrived in Munich may be momentarily perplexed by a sign

This article has been republished with minor changes. These changes do not impact the academic content of the article. 
placing her in München. Similarly, a Spaniard planning a trip to Londres may be distracted when London pops up on his laptop. Such variation of names occurs frequently in languages and emerges in a number of ways. For instance, Italian speakers use the anthroponym Cartesio (from the Latin Cartesius) to refer to the French philosopher René Descartes. Some well-known people and brand names (e.g., Barack Obama, Armani, McDonald's) retain their original written form but are modified to fit into a language's phonological system. Speakers' adaptation of names is a natural and frequent process in languages, which typically results from phonological, historical, and cultural influences in a language community, rather than through a translation process (Jordan 20I2; Woodman 20I2).

However, at times, translations of names are deliberately created, such as for product marketing or literary impact. For example, the names of the characters and creatures in J.K. Rowling's highly popular Harry Potter series have been translated to evoke the same sensibility in various languages as in the original English version (e.g., in Norway, the cat originally called Mrs. Norris is translated as Fru Hansen, and in Italy as Mrs. Purr). Swedes translate Gilderoy Lockhart as Gyllenroy Lockman, while Danes refer to the character as Glitterik Smørhair (Brøndsted and Dollerup 2004). Names are also altered in the dubbing of films, as illustrated by the renaming of characters in the Italian version of Star Wars movies (Leia becomes Leila, Han Solo is renamed Ian Solo, and Darth Vader is known as Lord Fener). Inexplicably, even alphanumeric names in Star Wars are altered in Italian, as with droids $R_{2}-D_{2}$ becoming $C_{I}-P 8$ [ $\mathrm{t} \int \mathrm{i}_{1}$ unopi'st:o] and C${ }_{3} P O$ renamed as $D_{-3} B O$ [di,trebi's] (Audissino, 20 I 2, p. I 8 Note I9).

Variation of toponyms and anthroponyms has been well documented in spoken languages, but is also documented in signed languages (Matthews et al. 2009; Revilla 2009; Paales 20II; Conte et al. 2013). ${ }^{\text {I }}$ For example, research on name signs for countries has shown that signers typically adopt the endonym of the country of origin (Matthews, McKee, and McKee 2009). ${ }^{2}$ Naming conventions in signed languages are shared by interacting with people from different geographic areas, viewing videos on the Internet that demonstrate name signs, taking courses in other signed languages, inter alia. In these ways, users of signed languages negotiate and standardize names from their native languages.

A challenge for signed language interpreters arises because they must convey names between languages that are expressed in two distinct modalities (signedspoken). When faced with interpreting a name, signed language interpreters do not have the option of simply repeating it verbatim from the source into the target text, as is possible in spoken language interpreting. In this paper we examine how signed language interpreters, specifically American Sign Language-English interpreters, manage names in discourse. Our aim is to describe the strategies employed by interpreting teams for rendering names that occur between languages that have two distinct modalities. We begin with an overview of naming practices in deaf communities followed by a discussion of the challenges that modality creates for signed language interpreters when conveying names. 


\section{Name signs in deaf communities}

In deaf communities, a "name sign" is a lexical form used to identify a specific person or place. Name signs are important identity markers because they denote membership in deaf communities for both deaf and hearing people. The use of name signs is well documented in deaf communities around the world (Meadow I977; Supalla 1992; Russo 1997; Matthews et al. 2009; Reck 2009; Paales 20II; Di Renzo, Conte and Petitta 2015; Nonaka et al. 2015). A summary of the scholars' findings on naming conventions in signed languages is provided below.

I. Fingerspelling-Name signs may be produced by fingerspelling ${ }^{3}$ (e.g., in American Sign Language, short names such as Marc or Val are often fully fingerspelled).

2. Initialization-Name signs may be produced by one or more handshapes that represent letters in the manual alphabet. Unlike fingerspelling, initialization uses a limited number of handshapes (e.g., first or last initial in a name) to represent a name (e.g., Roberta Jones may be initialized as R-J).

3. Literal translation-Name signs may be created from signs that already signify a lexical item (e.g., a person with the last name Baker may have a name sign that is the same as its semantic lexical correspondent) (Russo 1997; Peruzzi et al. 2000; Reck 2009).

4. Tradition-based names - Name signs may be created by borrowing a signed lexical item that links a historical, famous, or traditional figure to an individual who shares the same name (Russo 1997; Nonaka, et al. 2015). This may accomplished by describing an attribute associated with the well-known figure (e.g., In Italian Sign Language, a man named Francesco [English: Francis] may be assigned the name sign which represents the beard of St. Francis).

5. Description-Names signs may be created by using signed language to describe a characteristic (e.g., appearance, personality, role, or skill) of a person (e.g., a woman may have a name sign that indicates her blue eyes).

6. Combination-Finally, name signs may consist of a combination of approaches. For example, a name sign may be produced using the initial letter of a person's given name (\#2) articulated in a manner that represents a physical characteristic (\#5) (e.g., an R-handshape circling near the head to represent a curly-haired man named Robert).

Certain individuals who are well known in the deaf community worldwide have distinct name signs that are recognized by users of different signed languages (e.g., Thomas Hopkins Gallaudet, founder of the Gallaudet University in Washington, DC). Other individuals who are not members of the deaf community may be given a name sign because they are well-known figures (Bertone 
2005; Paales 20II; Di Renzo, Conte, and Petitta 2015). For example, U.S. President Jimmy Carter is often referred to by a descriptive name sign that characterizes his teeth. Imaginary or literary characters may also have name signs; for example, in Italy, Pinocchio has a name sign, as does Mickey Mouse in the U.S. ${ }^{4}$ Critically, there are constraints on where name signs can be produced on the body (e.g., face, head, torso, or space around the body). Unsurprisingly, as with names in spoken languages, name signs mirror the phonology and naming practices in the signed language in which they are used (Supalla I992).

In summary, name signs are conventionalized within deaf communities and can be linked to either the given name of the name-bearer (Approaches I-4), a characteristic of the individual (Approach 5), a combination of the two (Approach 6).

\section{Name as "problem triggers" in simultaneous interpreting}

Both Western and Eastern traditions of interpreting studies point out the difficulties of rendering names in simultaneous interpreting (Gile I984, I995; Carlet I998; Chernov 2004; Meier 2008). Lamberger-Felber (200I) found that unless interpreters have access to the original text in advance, they might omit names or render them erroneously. To mitigate the difficulty of rendering of names during interpretation, Gile (I995) points out the value of working in teams.

The challenges faced by signed language interpreters in rendering names may be illustrated in the example of an introduction between a deaf and hearing person. Frequently a deaf person will introduce himself in ASL by fingerspelling his name, immediately followed by his name sign, for example, "MY NAME A-R-D-A-V-A-N (A-handshape on-the-cheek)." 5 The first part of the sentence is easily interpreted into English as "My name is Ardavan"; however, the name sign (A-handshape on-the-cheek) does not have a corresponding form in English. This situation creates a quandary for the interpreter about how to express the ASL name sign into English.

Another challenge for signed language interpreters is that name signs often become so strongly associated with someone that the full name of the person is forgotten altogether (McKee and McKee 2000; Dean 20I4). In this situation, a deaf person may produce a name sign but the interpreter doesn't know who it represents, and is therefore unable to interpret it. Even when the interpreter knows the full name of the person, no information on the pronunciation of the name is available in a signed language so the interpreter must make a guess at how to correctly pronounce the name. Additionally, a name sign provides no clues into the gender of the person, leaving an interpreter unsure about which pronoun to use to reference the person. Finally, as name signs are neither universal nor represented in a written form, interpreters have little historical information on which to base their interpretation.

Such challenges have real-world implications for people who communicate through signed language interpreters. For example, in criminal court, a deaf 
witness may identify someone by a name sign, without knowing the person's full name, leaving the interpreter unable to make an accurate interpretation. Similarly, in an emergency room, a deaf person may produce an initialized P-handshape when discussing a medication, which could be misinterpreted as Prozac rather than Prednisone. To ameliorate possible misunderstandings, interpreters often work in teams of two or more, especially in high-stakes settings, complex language situations, and lengthy assignments (Hoza 2010).

In the U.S., the use of teams consisting of a deaf and hearing interpreter has become increasingly frequent in the past decade. Interpreters who are deaf and for whom ASL is their first language (aka native signers) often have a more extensive linguistic range than do hearing interpreters who learned a signed language as adults. The use of deaf interpreters is especially beneficial in highly complex language situations with a deaf person who is from another country and does not use American Sign Language. For example, a deaf-hearing interpreting team may be called to work in a hospital to mediate communication between an English-speaking physician and a deaf immigrant patient who uses Mexican Sign Language $\left(\mathrm{LSM}^{6}\right)$. In this scenario, when the physician asks the deaf patient a question in English (e.g., "What medications are you currently taking?"), the hearing interpreter conveys the question in ASL, which is viewed by the deaf interpreter. The deaf interpreter then renders the question from ASL into an alternative signed form, either Mexican Sign Language or a communication system known as International Sign. ${ }^{7}$ When the deaf patient answers the question, the deaf interpreter conveys the response in ASL, which is viewed by the hearing interpreter, who then interprets it in English for the physician. This complex situation of participants who use different languages requires the deaf and hearing interpreting team to manage a sequence of exchanges for the communication to be effective. But what strategies does the interpreting team use, both individually and collectively, to manage this type of interpreted exchange?

In this study we examine the strategies used by three deaf-hearing interpreting teams as they facilitate communication for a training session between a deaf international student and a hearing computer specialist. Specifically, we investigate the interpreters' management of name signs in the communicative event.

\section{Methods}

Three deaf-hearing teams of professional American Sign Language-English interpreters (hereafter identified as Teams I, 2, and 3 respectively) participated in this study. Teams I and 2 consisted of one male and one female, Team 3 consisted of two females. The age range of the interpreters was 30-65 and each of the interpreters was Caucasian. Each team member was regarded as an expert interpreter, with a range of 5-45 years of full-time professional work, national certification from Registry of Interpreters for the Deaf (RID), and experience interpreting across a variety of settings (e.g., medical, legal, educational). The interpreters resided in Boston and the Washington, DC metro area. They were 


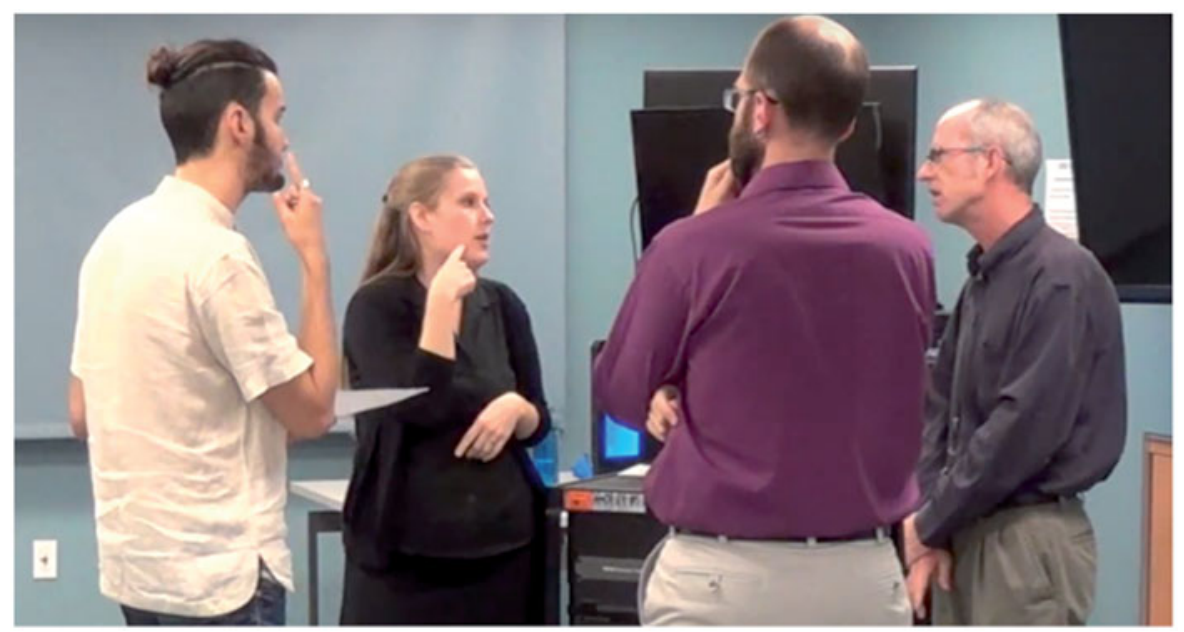

FIGURE 1. Image (from left to right) of the deaf Iranian student, the deaf interpreter, the hearing interpreter, and the hearing American trainer during the staged interaction.

recruited through personal contact and were compensated \$25 per hour for their participation in the study.

At the testing site (a language lab on a university campus), the researchers informed each deaf-hearing team that they would be video recorded as they interpreted a short (25-30 minute) computer training session between a hearing computer specialist (American) and a deaf college student from Iran. The interpreters were informed that the computer specialist would be using English and the deaf student would be using a combination of ASL and International Sign. See Figure I.

Prior to beginning the study, the researchers provided the deaf student and the hearing trainer with a semi-structured script to follow, and instructed them to use the following names in their discourse:

- Ardavan (name of deaf student)

- Tony (name of hearing trainer)

- Iran (name of country)

- Ahmadinejad (name of former president of Iran)

- Tehran (name of capital of Iran)

To begin, the interpreters were introduced to the deaf and hearing individuals who were engaged in the training session and given time to position themselves as needed. The interpreted interaction between the participants was video recorded by the researchers to make any visual information available for research purposes. Immediately following the interpreted training session, one researcher conducted video-recorded interviews in ASL with each of the interpreting teams together. The researcher engaged the team interpreters in a 
discussion about general strategies employed by the teams while interpreting the training session; however the interview data is not discussed in this paper.

To analyze the interpreting data, the video recordings of the interpretations were imported into ELAN, a video annotation software (http://tla.mpi.nl/tools/ tla-tools/elan/). One researcher did all of the coding, which was then corroborated by one other member of the research team. Each name occurrence was coded by type of management strategy used by the interpreters.

\section{Results}

In this section, we report on the strategies used by the team interpreters to convey names in the interpreted exchange. The identified strategies corresponded to those identified by Petitta, Halley, and Nicodemus (2016, 2018) in a study of hearing interpreters who were not part of a team. A description of the six strategies used by the interpreting teams (and an example from the data) is given below. We note that each of the strategies is used throughout the interpretations, not only to convey names, and all are viewed as acceptable ways for conveying the information.

I. Fingerspelling-The hearing interpreter conveys an English word into ASL by using the manual alphabet (e.g., for the name Tehran, the hearing interpreter fingerspells T-E-H-R-A-N). Note: This strategy is only possible in interpretations from English into ASL.

2. Pointing-The interpreter points to the name sign as it is being expressed in order to direct attention to its production (e.g., the hearing or deaf interpreter points to the deaf student as he produces his name sign).

3. Name Sign-The interpreter reproduces a name sign used in the source text (e.g., the interpreter reproduces the sign IRAN, without interpreting its English lexical equivalent). In instances in which the interpreter accompanies the name sign with the spoken name (e.g., reproducing the sign IRAN, while saying Iran), the interpreters are using Multiple Strategies. See Strategy \#6).

4. Name-The hearing interpreter produces an English equivalent for an ASL name sign when the deaf signer is modeling the sign (e.g., the deaf student signs IRAN and the hearing interpreter says "Iran" without pointing to the source or reproducing the name sign).

5. Description-The interpreter conveys a name by paraphrasing (e.g., to convey the name Tehran, the interpreter says "the capital of Iran"), or by describing how it should be articulated (e.g., for the sign IRAN, the interpreter describes the ASL production by saying "thumb touching the palm").

6. Multiple Strategies-The interpreter uses a combination of two or more strategies described above for rendering a single name (e.g., for 


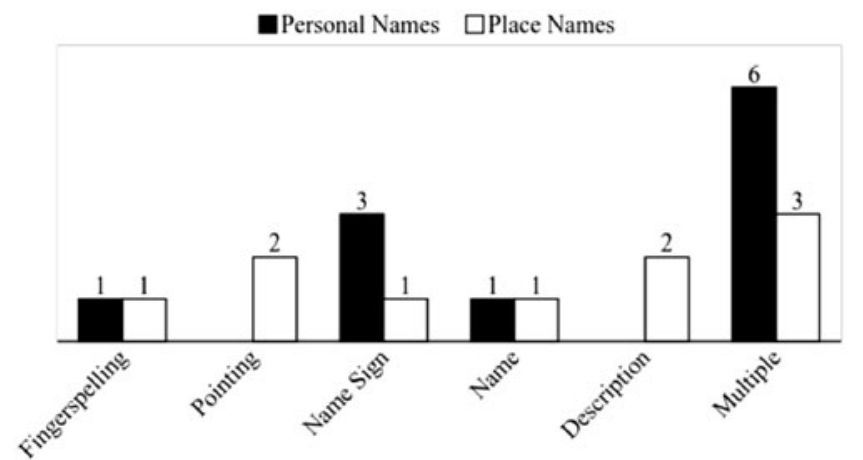

FIGURE 2. Frequency of interpreters' strategies used to interpret name signs from ASL into English for the total of name items.

the sign IRAN, the hearing interpreter says, "The sign is articulated with two hands" while simultaneously modeling the sign). Multiple Strategies may include a variety of combinations (e.g., Fingerspelling + Pointing) in a serial or simultaneous fashion both when interpreting from ASL into English, and vice versa.

\section{Interpretations from ASL into English}

A total of 2I names were translated from ASL into English. Notably, when conveying name signs from ASL into English. the team interpreters exhibited a variety of strategies (see Figure 2). This was in marked contrast to the number of strategies used when interpreting from English into ASL (see Figure 3). When interpreting from ASL into English, the deaf interpreter and the hearing interpreter both used the same strategies to convey a single name sign. This occurred with Team I and Team 2. For example, when interpreting TEHRAN, both the deaf and hearing interpreter in Team I used Description (i.e., the deaf interpreter signed "CAPITAL OF IRAN," which was followed by the hearing interpreter saying, "The capital of Iran"). Similarly, when interpreting the name sign for Iran's former president Ahmadinejad, both interpreters in Team 2 used Multiple Strategies (Pointing + Description, see Figure 4).

The use of Multiple Strategies was found to be the most frequently used approach to convey both anthroponyms and toponyms from name signs into English (see Figure 4 for details about the combination of strategies).

\section{Interpretations from English into ASL}

Interpretations from English into ASL exhibited less variation in the range of strategies than when interpreting in the other direction. The use of the same strategies within teams is consistent: each of the three teams used the same strategy each time. Only two strategies were used to convey names from English 


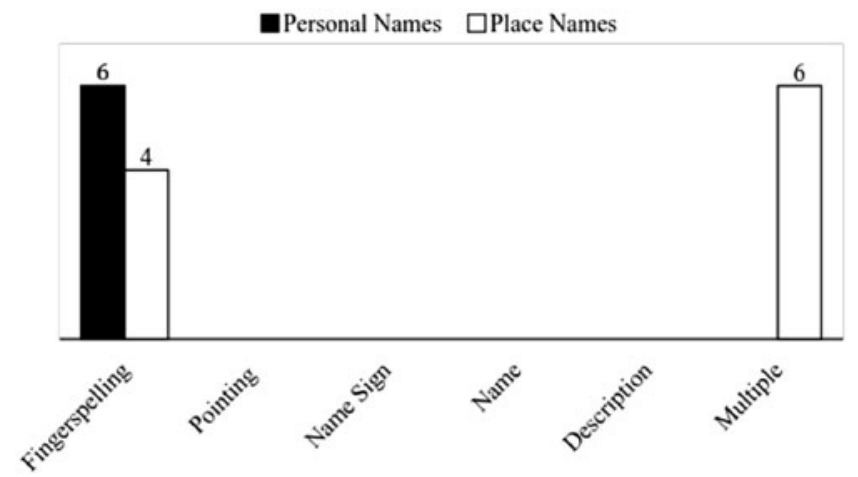

FIGURE 3. Frequency of interpreters' strategies used to interpret names from English into ASL for the total of name items.

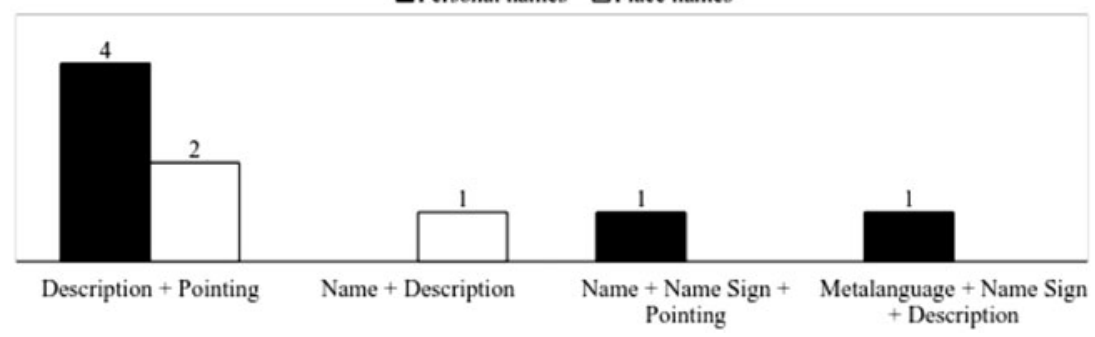

FIGURE 4. Frequency of the types of Multiple Strategies utilized in ASL-to-English interpretations.

into ASL: Fingerspelling and Multiple Strategies (see Figure 3). Furthermore, Multiple Strategies always included the modeling of the name sign produced by the deaf student, accompanied by a second strategy (see Figure 5). It is worth noting that only toponyms were interpreted into English by using two different strategies: Fingerspelling and Multiple Strategies. Anthroponyms were interpreted only by Fingerspelling.

\section{Discussion}

In our investigation of strategies used by signed language interpreters to render names, we found differences between the interpretations of personal vs place names, and between interpretations into ASL vs spoken English. Our results reveal numerous strategies for interpreting names between a spoken and signed language. These findings add to the literature that points to the challenging nature of translating names and at the same time suggest that there is no single solution to address this challenge.

Although the sample is limited to three teams of interpreters, we note that the use of Multiple Strategies (the combination of two or more strategies) is the 


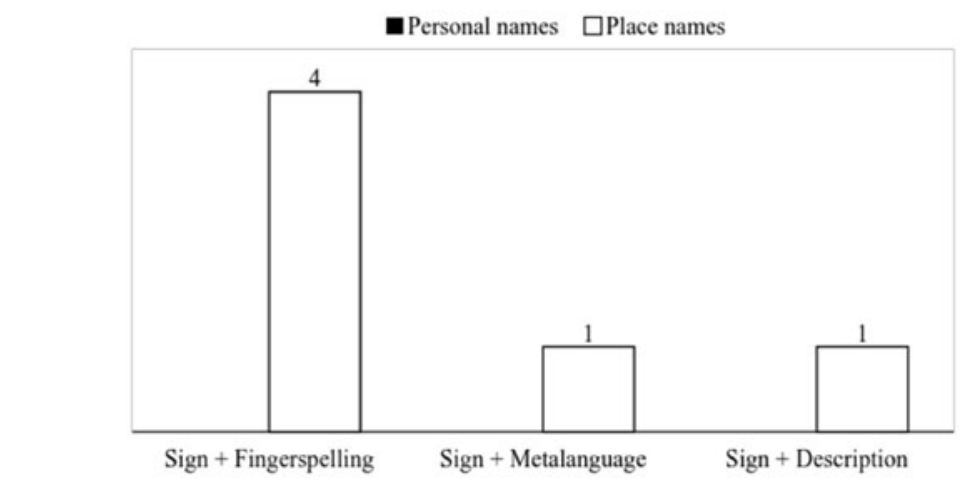

FIGURE 5. Frequency of the types of Multiple Strategies utilized in English-to-ASL interpretations.

most frequent solution employed by the interpreters. Those results mirror the findings discussed in Petitta et al. (2016, 2018) in which interpreters also used Multiple Strategies as the most frequent approach in their interpretations. In this study, interpreters often conveyed the name in two (or more) different ways (e.g., Name Sign + Fingerspelling). We speculate this occurred because of the desire to preserve the original form of the name in some way in the interpretation.

As described earlier in the paper, interpreters may be unsure of the spelling (or pronunciation) of a name; thus they render as much information as possible for the interlocutor (by conveying the name sign or pointing toward it if it is signed by one of the participants) and to preserve the original form in case the official name needs to be mentioned. This type of interpretation follows McKee and McKee's (2000) suggestion about the difficulty of providing a spoken version of a name sign without having the complete information about the person the name denotes.

In English into ASL interpretation, Multiple Strategies always included Modeling in combination with other approaches. In one instance, it was noted that the sign IRAN used by the deaf interlocutor was the same sign that means DEAF CLUB in American Sign Language (see Figure 6).

This dual meaning representation of signs resulted in misunderstanding and generated discussions between the deaf interpreter and the deaf student, as well as between the deaf-hearing team interpreters. In this case, the use of Multiple Strategies undoubtedly unfolded because after the interpreters had conveyed the message from the deaf student ("I am from Iran"), a subsequent metalinguistic discussion started ("How did you sign Iran? I thought that was the sign for DEAF CLUB!"). Such discussions interrupt the flow of the conversation and are particularly challenging to manage, because interpreters - once again-must convey the original form as well as the function of the name in the discourse. In such situations, as well as in cases when one of the interpreters is unsure of the spelling of a name, some type of interaction between interpreters is necessary. 


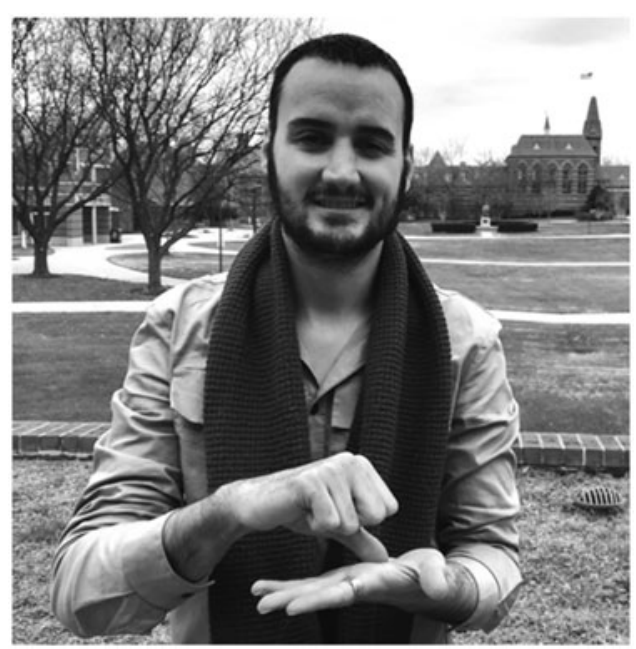

FIGURE 6. Image of sign for IRAN in Iranian Sign Language and DEAF CLUB in American Sign Language.

Interpreters interacted primarily to request clarifications (spelling, meaning, nature, and form of a sign or a word) of names that were produced by either the deaf or hearing member of the interpreting team.

\section{Conclusion}

In this paper we report on the strategies used by deaf-hearing signed language interpreting teams to convey names when interpreting an interaction between a deaf student and a hearing trainer. Our results show that interpreting culturally marked items such as names is challenging in communication across language modalities. The challenges are intensified by the time constraints of simultaneous interpreting, as well as the dynamics of deaf-hearing team interpreting managing two different language modalities (sign vs speech) with a complex turn-taking dynamics (hearing speaker-hearing interpreter-deaf interpreter-deaf signer and vice versa).

We found that signed language interpreters most often use Multiple Strategies to render names from one language into another, which seems necessary given the distinct modalities of each of their working languages. It is actually possible to talk while signing at the same time, and multimodal multiple strategies (sign+ speech (description, metalanguage, etc.) see fig. 4 and 5) are a convenient linguistic strategy for this reason.

The variety of strategies used by interpreters, as well as the non-significant differences between the English into ASL and the ASL into English interpretations shown in our data, suggest that it is unusual to offer a single solution for rendering names in multilingual interactions: instead, interpreters draw from a range of possibilities. In negotiating the form and meaning of names (in both English and ASL), having metalinguistic discussions, and requesting clarifications from 
the interpreters and interlocutors are characteristics that need further investigation. Results will indicate what challenges are unique to signed language interpreters and, further, determine if the strategies used to convey names apply to other dilemmas in signed language interpretation. It is important to note how the teaming up itself (and the necessity of translating from English into ASL and then from ASL into a second signed language-and vice versa) can represent both a challenge and its solution, since despite the complexity of the interaction, the collaboration between interpreters is crucial in making the dialogue effective.

Critically, our data suggests the particular linguistic status of names and name signs and suggest the importance of investigating their management in translation and interpreting. Looking at the functions and dynamics of multilingual discourse offers new insights in the study of names. In particular, the functionand the discussions generated by the use of names-warrants investigation in order to provide a deeper understanding of the very nature of names.

\section{Acknowledgments}

We also extend our heartfelt thanks to each of the individuals who graciously participated in the study.

\section{Notes}

I. Despite popular belief, signed languages are not universal; just as speakers from different areas have unique spoken languages, deaf communities also have distinct signed languages.

2. To date, the United Nations Group of Experts on Geographical Names (UNGEGN) does not include signed languages.

3. Fingerspelling is a set of handshapes representing written letters of an alphabet. This "manual alphabet" is used in signed languages to represent names or words that do not have a corresponding sign or to express a particular function in the discourse (Nicodemus et al. 20I7).

4. Mickey Mouse is an example of how names can vary across language. The cartoon character is so popular that it has been assigned an Italian name: Topolino. Interestingly, the character has one name sign in American Sign Language and a different name sign in Italian Sign Language.

5. Conventions in transcribing ASL include using capitalized glosses to represent signs, hyphens to indicate fingerspelling, and parentheses to describe information that does not take a single English lexical form.

6. LSM stands for Lengua de Señas Mexicana.

7. International Sign (IS) is used as a means of communication at some international gatherings of signers. IS relies on iconic features and vocabulary derived from different signed languages.

\section{Disclosure statement}

No potential conflict of interest was reported by the author.

\section{Funding}

We are grateful for funding support of this project from the Gallaudet University Office of Research Support and International Affairs (RSIA). 


\section{Bibliography}

Audissino, Eminio, 20I2. Italian doppiaggio. Dubbing in Italy: Some notes and (In)famous examples. Italian Americana 30(I): 22-32.

Brøndsted, Katrine, and Cay Dollerup. 2004. The names in Harry Potter. Perspectives: Studies in Translatology I 2(I): 56-72.

Carlet, Laura. I998. G.V. Chernov's psycholinguistic model in simultaneous interpretation: An experimental contribution. The Interpreter's Newsletter 8: 75-92.

Chernov, Ghelly V. 2004. Inference and anticipation in simultaneous interpreting: A probability-prediction model. Amsterdam: John Benjamins.

Conte, Serena, Alessio Di Renzo, Giulia Petitta, Paolo Rossini, and Virginia Volterra. 2013. Sign language toponymy in Italy: Synchronic and diachronic variation. Paper presented at the Trends in Toponymy 6 Conference, Oct. 7-Io, Heidelberg, Germany.

Dean, Robyn K. 20I4. Condemned to repetition? An analysis of problem-setting and problem-solving in sign language interpreting ethics. Translation \& Interpreting 6(I): 60-75.

Di Renzo, Alessio, Serena Conte, and Giulia Petitta. 20I 5. Deaf communities through the name signs lens: Language, community, identity. Paper presented at the First Worldwide Congress for Language Rights, May I9-23, Teramo, Italy.

Gile, Daniel. I984. Les noms propres en interprétation simultanée. Mutlilingua 3 (2): 79-85.

Gile, Daniel. 1995. Basic concepts and models for translator and interpreter training. Amsterdam: John Benjamins.

Hoza, Jack. 20 Iо. Team interpreting as collaboration and interdependence. Alexandria, VA: RID Press.

Jordan, Peter. 20I2. Place names as ingredients of space-related identity. Oslo Studies in Language 4 (2): II 7-I3I.

Lamberger-Felber, Heike. 200I. Text-oriented research into interpreting. Examples from a case study. Journal of Linguistics 26: 39-64.

Matthews, Phillip W., Rachel L. McKee, and David McKee. 2009. Signed languages, linguistic rights and the standardization of geographical names. In Names in multi-lingual, multi-cultural and multi-ethnic contact. Proceedings of the 23 rd International Congress of Onomastic Sciences, Eds. Wolfgang Ahrens, Sheila Embleton, and André Lapierre, 72I-732. Toronto: York University.

McKee, Rachel, and David McKee. 2000. Name signs and identity in New Zealand Sign Language. In Bilingualism and identity in deaf communities. Ed. Melanie Metzger, 3-40. Washington, DC: Gallaudet University Press.

Meadow, Kathryn P. I977. Name signs as identity symbols in the deaf community. Sign Language Studies I 6(I): $237-246$.

Nicodemus, Brenda, Laurie Swabey, Lorraine Leeson, Jemina Napier, Giulia Petitta, and Marty Taylor. 2017. A cross-linguistic analysis of fingerspelling production by sign language interpreters. Sign Language Studies I7(2): I43-I7I.

Nonaka, Angela, Kate Mesh, and Keiko Sagara. 2015. Signed names in Japanese Sign Language: Linguistic and cultural analyses. Sign Language Studies I 6(I): 57-85.

Paales, Liina. (20I I). Name signs for hearing people. Folklore: Electronic Journal of Folklore 47: 43-76.

Peruzzi, Anna-Maria, Paolo Rossini, Tomasso Russo, and Virginia Volterra. 2000. Segni nome ed identità personale nella LIS. In Viaggio nella città invisibile. Atti del II Convegno nazionale sulla LIS. Eds. Caterina Bagnara, Giampaolo Chiappini, Maria Pia Conte, and Michela Ott, 488-494. Pisa, Italy: Edizioni del Cerro.

Petitta, Giulia, Mark Halley, and Brenda Nicodemus. 20I6. Managing metalinguistic references in bimodal interpreted discourse: An analysis of an American Sign Language-English interpretation. Rivista di Psicolinguistica Applicata I6(2): 53-69.

Petitta, Giulia, Mark Halley, and Brenda Nicodemus. 20г8.'What's the sign for nitty gritty?' Managing metalinguistic references in ASL-English dialogue interpreting. Translation and Interpreting Studies I $3(\mathrm{I}): 50-72$.

Reck Anne-Kathrin. 2009. Pointy helmets and buck teeth: Naming in sign language - An exploration. In Names in multi-lingual, multi-cultural and multi-ethnic contact. Proceedings of the 23 rd International Congress of Onomastic Sciences. Eds. Wolfgang Ahrens, Sheila Embleton, and André Lapierre, 828-836. Toronto: York University.

Revilla, Bettina. 2009. Place names in Israeli Sign Language. MA thesis, University of North Dakota. 
Russo, Tomasso. 1997. Segni nome e identità culturale nella comunità sorda in Italia. In Del gesto, cultura della parola. Viaggio antropologico nel nondo dei sordi, Ed. Amir Zuccalà, 68-82. Rome: Meltemi.

Supalla, Samuel J. I992. The book of name signs: Naming in American Sign Language. San Diego, CA: DawnSign Press.

Woodman, Paul. Ed. 20I2. The great toponymic divide: Reflections on the definition and usage of endonyms and exonyms. Warsaw: Head Office of Geodesy and Cartography.

\section{Notes on contributors}

Giulia Petitta is an Italian interpreter and linguist. She has been doing research with several institutions in Italy and the U.S.

Valerie Dively is Professor in the Department of Interpretation and Translation at Gallaudet University.

Mark Halley is a doctoral candidate in the Department of Interpretation and Translation at Gallaudet University. He is currently conducting his dissertation research on the role of American Sign Language-English interpreters during the I988 Deaf President Now protest.

Marc Holmes is a doctoral student in the Department of Interpretation and Translation and a working staff interpreter at Gallaudet University.

Brenda Nicodemus is Professor in the Department of Interpretation and Translation at Gallaudet University and Director of the Gallaudet Center for the Advancement of Interpreting and Translation Research.

Correspondence to: Brenda Nicodemus brenda.nicodemus@gallaudet.edu Gallaudet University, 800 Florida Avenue NE, Washington, DC 200023695 , USA. 